\title{
DURATION OF BREASTFEEDING AND PSYCHOMOTOR DEVELOPMENT IN 1-YEAR-OLD CHILDREN - POLISH MOTHER AND CHILD COHORT STUDY
}

\author{
IWONA STELMACH ${ }^{1}$, PAULINA KWARTA ${ }^{1}$, JOANNA JERZYŃSKA ${ }^{1}$, WŁODZIMIERZ STELMACH ${ }^{2}$, \\ JAN KRAKOWIAK ${ }^{2}$, MICHAŁ KARBOWNIK ${ }^{3}$, DANIELA PODLECKA ${ }^{1}$, WOJCIECH HANKE ${ }^{4}$, \\ and KINGA POLAŃSKA ${ }^{4}$
}

${ }^{1}$ Medical University of Lodz, Łódź, Poland

Copernicus Memorial Hospital in Łódź, Department of Pediatrics and Allergy

${ }^{2}$ Medical University of Lodz, Łódź, Poland

Department of Social and Preventive Medicine

${ }^{3}$ Medical University of Lodz, Łódź, Poland

Department of Pharmacology and Toxicology

${ }^{4}$ Nofer Institute of Occupational Medicine, Łódź, Poland

Department of Environmental Epidemiology

\begin{abstract}
Objectives: The objective of this study was to evaluate the association between breastfeeding duration and child neurodevelopment based on the Polish Mother and Child Cohort Study. Material and Methods: The current analysis included 501 mother-child pairs. The analysis evaluating the association between the length of breastfeeding and child neurodevelopment considered the following variables: maternal age and body mass index, weight gain during pregnancy, parental level of education, marital status, socioeconomic status, child gender, birthweight, type of delivery, preterm delivery, pre- and postnatal exposure to tobacco constituents and child day care attendance. Psychomotor development was assessed in 1-year-olds on the Bayley Scales of Infant and Toddler Development. Results: The length of breastfeeding correlated positively with maternal age at delivery $(\varrho=0.13)$, maternal and paternal level of education $(\varrho=0.2$ and $\varrho=0.14$ respectively), birthweight $(\varrho=0.1)$ and marital status $(\varrho=0.16)(p<0.05)$. A negative correlation between the length of breastfeeding and maternal smoking status during the first year after delivery $(\varrho=-0.19)$ and weight gain during pregnancy $(\mathrm{r}=-0.1)$ was observed $(\mathrm{p}<0.05)$. The association between the duration of breastfeeding and child development was not statistically significant in the model with the inclusion of confounding variables. A significant association between language development and maternal level of education $(\mathrm{p}=0.004)$, gender of the child $(\mathrm{p}=0.0007)$ and maternal weight gain during pregnancy $(\mathrm{p}=0.01)$ was found. A negative association between cognitive development and maternal salivary cotinine during pregnancy $(\mathrm{p}=0.03)$ and a negative association between motor development and maternal smoking status during the first year after delivery $(\mathrm{p}=0.007)$ were also found. Conclusions: This study found no significant association between the duration of breastfeeding and child development after adjustment for confounders. Int J Occup Med Environ Health. 2019;32(2):175-84
\end{abstract}

Key words:

children, neurodevelopment, duration of breastfeeding, child psychomotor development, Bayley Scales of Infant and Toddler Development, 1-year-old children

Funding: this study was supported by National Science Centre (grant No. DEC-2014/15/B/NZ7/00998 entitled "Role of maternal lifestyle-related factors during pregnancy and exposure after birth in children's health and neurodevelopment at age of 7 years," grant manager: Kinga Polańska, Ph.D.).

Received: February 6, 2018. Accepted: June 15, 2018.

Corresponding author: Iwona Stelmach, Medical University of Lodz, Copernicus Memorial Hospital in Łódź, Department of Pediatrics and Allergy, Piłsudskiego 71, 90-329 Łódź, Poland (e-mail: alergol@kopernik.lodz.pl). 


\section{INTRODUCTION}

Child cognitive development has genetic background [1]. In addition, it may be beneficially influenced by environmental and lifestyle-related factors (adequate nutrition, parental attention, stimulation at home) [2]. Many studies report positive associations between breastfeeding and child neurodevelopment [3-7] and suggest that longer duration of breastfeeding benefits child psychomotor development $[8,9]$. In some studies, however, the correlation between breastfeeding and psychomotor development of children is not statistically significant after adjustment for confounding variables [10-14].

It is not clear whether the better psychomotor development is due to the beneficial properties of breast milk or residual confounding. Positive effects of breastfeeding on child neurodevelopment were hypothesized to be mediated by long-chain polyunsaturated fatty acids (PUFA) which are present in human milk, but not in cow's milk or most infant formulas [14]. Yet a systematic review of all randomized trials where maternal diet was supplemented with PUFAs during pregnancy failed to confirm such an effect [14-16]. The meta-analysis by Jain et al. implied that $<25 \%$ of studies into this topic had adjusted for sociodemographic confounders [17]. In addition, the latest systematic review by Walfisch et al. also pointed out that much of the reported effect of breastfeeding on child neurodevelopment is due to confounding and concluded that future studies should attempt to rigorously control for all important confounders [14]. Among a variety of factors, demographic and IQ differences between mothers who breastfeed and those who choose not to are the most frequently underlined.

The aim of this study was to evaluate whether duration of breastfeeding is associated with child neurodevelopment, taking into account confounders such as maternal age, pre-pregnancy body mass index (BMI), weight gain during pregnancy, parental level of education, marital status, socioeconomic status, pre- and postnatal expo- sure to tobacco constituents, child gender, birthweight, type of delivery, preterm delivery and child day care attendance.

\section{MATERIAL AND METHODS \\ Study design and population}

The present study was part of the Polish Mother and Child Cohort (REPRO_PL), a multicenter prospective cohort study performed in different regions of Poland looking into environmental factors contributing to pregnancy outcomes, children's health and neurodevelopment that had been established in 2007-2011. The study was approved by the Ethical Committee of the Nofer Institute of Occupational Medicine, Łódź, Poland (Decisions No. 7/2007 and 3/2008). Written informed consent was obtained from all participants included in the study.

Women were recruited during the first trimester of pregnancy at maternity units in selected regions of Poland provided they fulfilled the following inclusion criteria: single pregnancy up to 12 weeks of gestation, no assisted conception, no pregnancy complications and no chronic diseases as specified in the study protocol. Questionnaires and biological samples (saliva for smoking status assessment) were collected during pregnancy (weeks: 8-12, 20-24 and 30-34) and at birth. The questionnaires covered sociodemographic data, medical and reproductive history, and information about environmental, lifestyle and occupational factors. Each child's exposure to environmental factors, health status and neurodevelopment were assessed a year after the child's birth. The current analysis, taking into account the availability of data, was restricted to 501 (out of 538; 93\%) children. The study procedures are described in detail elsewhere $[18,19]$.

\section{Child neurodevelopment assessment}

The Bayley Scales of Infant and Toddler Development were applied to assess children's neurodevelopment at around 
$12( \pm 1.5)$ months. Details regarding child psychomotor assessment have been published before [19-23]. Examination was performed at pediatric medical centers at 2 university hospitals in Łódź and Legnica. The testing was done in the presence of the mother or a relative by a trained psychologist or a child development specialist. The current analysis has focused on child cognitive, language and motor development. Child psychomotor development measured by raw score/chronological age was yielded with each subtest, and composite scores for language, motor scales and a composite score equivalent for the cognitive scale were generated on the basis of such data [19].

\section{Confounding variables}

The covariates considered in the analysis were as follows: maternal age at delivery, pre-pregnancy BMI, weight gain during pregnancy, parental level of education (highest level of completed education), marital status, socioeconomic status, maternal salivary cotinine during pregnancy, child passive smoking status within 1 year after birth (based on maternal smoking status during the first year after delivery and child urinary cotinine at 1 year of age), child gender, birthweight, type of delivery, preterm delivery and child day care attendance. Details regarding the assessment of the variables have been published previously [20-23].

\section{Statistical analysis}

Continuous variables were described as the mean and standard deviation (SD), whereas categorical variables as absolute and relative frequencies. Correlations between the length of breastfeeding and selected variables were assessed using Spearman's @. The false discovery rate (FDR) for the correlations was controlled at the level of 0.05 with the Benjamini and Hochberg correction for testing multiple hypotheses. The association between Bayley test results and length of breastfeeding was assessed in the following steps:
1. Univariate regression models were built.

2. Potential covariates were listed based on the literature review and previous assessments done based on REPRO_PL cohort [20-23]. The confounding effect of the examiner who performed the test was also included. Potential covariates were evaluated with the mean of Spearman's @ $(\mathrm{p}<0.1)$.

3. The initially identified covariates were included in the multivariate model and a multivariate backward stepwise regression analysis was carried out to yield models explaining Bayley test results.

P-value $<0.05$ was considered statistically significant in the final analyses. The analyses were performed using STATISTICA 12.5 Software (StatSoft, Tulsa, OK, USA).

\section{RESULTS}

\section{Descriptive analysis}

Parental and child characteristics are presented in Table 1. The mean maternal age at delivery was $28.8 \pm 4.4$ years and pre-pregnancy BMI was $22.4 \pm 3.7 \mathrm{~kg} / \mathrm{m}^{2}$. The mean maternal weight gain over pregnancy was $12.4 \pm 4.7 \mathrm{~kg}$. Most of the mothers (62\%) and $38.8 \%$ of the fathers had a university degree. A high proportion of the women were married (75.1\%). About $70 \%$ of parents had a middle socioeconomic status, while about $11 \%$ of the mothers had a low socioeconomic status and $19 \%$ had a high socioeconomic status. About $12 \%$ of the mothers were active smokers during pregnancy. Forty-six percent of the mothers breastfed $>6$ months, while $10 \%$ declared no breastfeeding of their child.

On average, the children were born at the 39th week of gestation with the mean birth weight of $3.33 \mathrm{~kg}$. About $53 \%$ of the children were girls. Sixty-four percent of the mothers had vaginal delivery. Although $83 \%$ of the mothers declared that they didn't smoke during the first year after delivery, about $50 \%$ of the children had a passive smoking status (resulting from parental or other household member smoking). 
Table 1. Sociodemographic characteristics of parents and children who participated in the study

\begin{tabular}{|c|c|c|}
\hline \multirow{2}{*}{ Variable } & \multicolumn{2}{|c|}{ Respondents } \\
\hline & $\mathrm{n}(\%)$ & $\mathrm{M} \pm \mathrm{SD}$ \\
\hline \multicolumn{3}{|l|}{ Parents } \\
\hline maternal age at delivery $(\mathrm{N}=501)$ [years] & & $28.8 \pm 4.4$ \\
\hline maternal pre-pregnancy BMI $(\mathrm{N}=501)\left[\mathrm{kg} / \mathrm{m}^{2}\right]$ & & $22.4 \pm 3.7$ \\
\hline maternal weight gain over pregnancy $[\mathrm{kg}](\mathrm{N}=477)$ & & $12.4 \pm 4.7$ \\
\hline \multicolumn{3}{|l|}{ maternal level of education $(\mathrm{N}=500)$} \\
\hline primary/vocational & $21(4.2)$ & \\
\hline secondary & $169(33.8)$ & \\
\hline university & $310(62.0)$ & \\
\hline \multicolumn{3}{|l|}{ paternal level of education $(\mathrm{N}=492)$} \\
\hline primary/vocational & $24(4.9)$ & \\
\hline secondary & $277(56.3)$ & \\
\hline university & $191(38.8)$ & \\
\hline \multicolumn{3}{|l|}{ marital status $(\mathrm{N}=497)$} \\
\hline married & $373(75.1)$ & \\
\hline unmarried & $124(24.9)$ & \\
\hline \multicolumn{3}{|l|}{ socioeconomic status $(\mathrm{N}=494)$} \\
\hline low & $55(11.1)$ & \\
\hline middle & $345(69.8)$ & \\
\hline high & $94(19.0)$ & \\
\hline \multicolumn{3}{|l|}{ maternal smoking status during pregnancy $(\mathrm{N}=501)$} \\
\hline yes & $60(12)$ & \\
\hline no & $441(88)$ & \\
\hline \multicolumn{3}{|l|}{$\begin{array}{l}\text { maternal smoking status during the first year after delivery } \\
(\mathrm{N}=497)\end{array}$} \\
\hline yes & $87(17.5)$ & \\
\hline no & $410(82.5)$ & \\
\hline \multicolumn{3}{|l|}{ breastfeeding $(\mathrm{N}=501)$} \\
\hline 0 months & $52(10.4)$ & \\
\hline$\leq 3$ months & $133(26.5)$ & \\
\hline$>3$ and $\leq 6$ months & $85(17.0)$ & \\
\hline$>6$ months & $231(46.1)$ & \\
\hline \multicolumn{3}{|l|}{ Children } \\
\hline birthweight $(\mathrm{N}=431)[\mathrm{kg}]$ & & $3.33 \pm 0.48$ \\
\hline \multicolumn{3}{|l|}{ gender of the child $(\mathrm{N}=501)$} \\
\hline girl & $265(52.9)$ & \\
\hline boy & $236(47.1)$ & \\
\hline
\end{tabular}


Table 1. Sociodemographic characteristics of parents and children who participated in the study - cont.

\begin{tabular}{lc}
\hline \multicolumn{1}{c}{ Variable } & Respondents \\
\cline { 2 - 2 } $\begin{array}{l}\text { Children - cont. } \\
\text { type of delivery }(\mathrm{N}=449)\end{array}$ & $\mathrm{n}(\%)$ \\
$\quad$ vaginal & $287(63.9)$ \\
$\quad$ caesarean & $162(36.1)$ \\
preterm delivery (before 38th week) $(\mathrm{N}=501)$ & \\
yes & $51(10.2)$ \\
no & $450(89.8)$ \\
day care attendance $(\mathrm{N}=463)$ & \\
yes & $34(7.3)$ \\
no & $429(92.7)$ \\
child passive smoking status $(\mathrm{N}=501)$ & \\
yes & $251(50.1)$ \\
no & $250(49.9)$ \\
\hline
\end{tabular}

\section{Inferential analysis}

Correlations of breastfeeding with selected sociodemographic and child variables are presented in Table 2. Breastfeeding correlated positively with maternal age at delivery $(\varrho=0.13)$, maternal and paternal levels of education ( $\varrho=0.2$ and $\varrho=0.14$ respectively), birthweight $(\varrho=0.1)$, and marital status $(\varrho=0.16)$ (Benjamini and Hochberg corrected $\mathrm{p}<0.05$ ), while a negative breastfeeding correlation with the maternal smoking status during the first year after delivery $(\varrho=-0.19)$ and maternal weight gain over pregnancy $(\varrho=-0.1)$ was observed (Benjamini and Hochberg corrected $\mathrm{p}<0.05$ ). No significant correlations between breastfeeding and maternal pre-pregnancy BMI, socioeconomic status, gender of the child, type of delivery, preterm delivery and day care attendance were found. The correlation between breastfeeding and child passive smoking status was of borderline significance.

Table 3 shows the association between the duration of breastfeeding and child development, adjusted for confounders. The association between the duration of breastfeeding and child development was not statistically sig- nificant. The association between language development and maternal level of education ( $p=0.004)$, gender of the child $(\mathrm{p}=0.0007)$ and maternal weight gain during pregnancy ( $p=0.01$ ) was found. In addition, negative associations between maternal salivary cotinine during pregnancy and cognitive development ( $\mathrm{p}=0.03$ ), as well as maternal smoking status during the first year after delivery and child motor development $(p=0.007)$ were found.

\section{DISCUSSION}

In the study group, a multivariate analysis showed that maternal level of education, gender of the child, maternal weight gain during pregnancy and maternal smoking status during pregnancy and after delivery were significant confounders of the association between the duration of breastfeeding and 1-year-old child psychomotor development. As opposed to several studies [3-9] the association between the duration of breastfeeding and 1-year-oldchild psychomotor development was not confirmed. Other authors observed that the duration of breastfeeding did not predict child psychomotor development [24]. Der et al. 
Table 2. Correlations between breastfeeding and selected sociodemographic variables

\begin{tabular}{|c|c|c|}
\hline Variable & Spearman's @ & $\mathrm{p}$ \\
\hline \multicolumn{3}{|l|}{ Parents } \\
\hline \multicolumn{3}{|l|}{ mother } \\
\hline age at delivery & 0.13 & 0.0026 \\
\hline pre-pregnancy BMI & -0.08 & 0.0752 \\
\hline weight gain over pregnancy & -0.10 & 0.0437 \\
\hline level of education & 0.20 & $<0.0001$ \\
\hline marital status (married -1 , unmarried -0 ) & 0.16 & 0.0003 \\
\hline socioeconomic status & 0.03 & 0.5251 \\
\hline smoking during the first year after delivery (yes -1, no -0 ) & -0.19 & $<0.0001$ \\
\hline \multicolumn{3}{|l|}{ father } \\
\hline level of education & 0.14 & 0.0015 \\
\hline \multicolumn{3}{|l|}{ Children } \\
\hline birthweight & 0.10 & 0.0285 \\
\hline gender of the child (girl - 1, boy - 0 ) & -0.03 & 0.4901 \\
\hline type of delivery (caesarean -1 , vaginal -0 ) & -0.09 & 0.0536 \\
\hline preterm delivery (before 38 week) (yes -1 , no - 0 ) & -0.06 & 0.1683 \\
\hline day care attendance (yes -1 , no -0 ) & -0.06 & 0.2197 \\
\hline child passive smoking status (yes -1, no -0 ) & -0.09 & 0.0518 \\
\hline
\end{tabular}

Bolded - significant correlations which survived Benjamini and Hochberg correction for testing multiple hypotheses (false discovery rate $=0.05$ ). The corrected significance level is 0.0179 .

concluded that breastfeeding has little or no effect on the child's intelligence [25].

The prospective study design constitutes an important advantage of this study. Additionally, a series of detailed questionnaires (and biomarker measurements) made it possible to reliably assess the confounding variables. Restricting this study population to healthy women allowed the authors to eliminate additional confounding factors, though the authors had to consider the possibility that other unmeasured risk factors (e.g., children's maternal relationship and home environment) produced associations between the exposures of interest and child neurodevelopment. In the current analysis, the authors assessed multiple aspects of child neurodevelopment by a well-standardized and widely used tool for early and fairly comprehensive measures.
This analysis included important potential confounders of the relationship between the duration of breastfeeding and 1-year-old child psychomotor development.

Multiple linear models were constructed in this study, incorporating many confounders, showing statistically significant correlations between language development and maternal level of education, gender of the child and maternal weight gain during pregnancy and between motor development and maternal smoking status after delivery as well as between cognitive development and maternal smoking during pregnancy. Most of the observed associations between breastfeeding and cognitive development in other studies were the result of confounding by maternal intelligence [14]; the level of cognitive stimulation at home, mother's educational attainment and family financial hardship all have independent effects. 


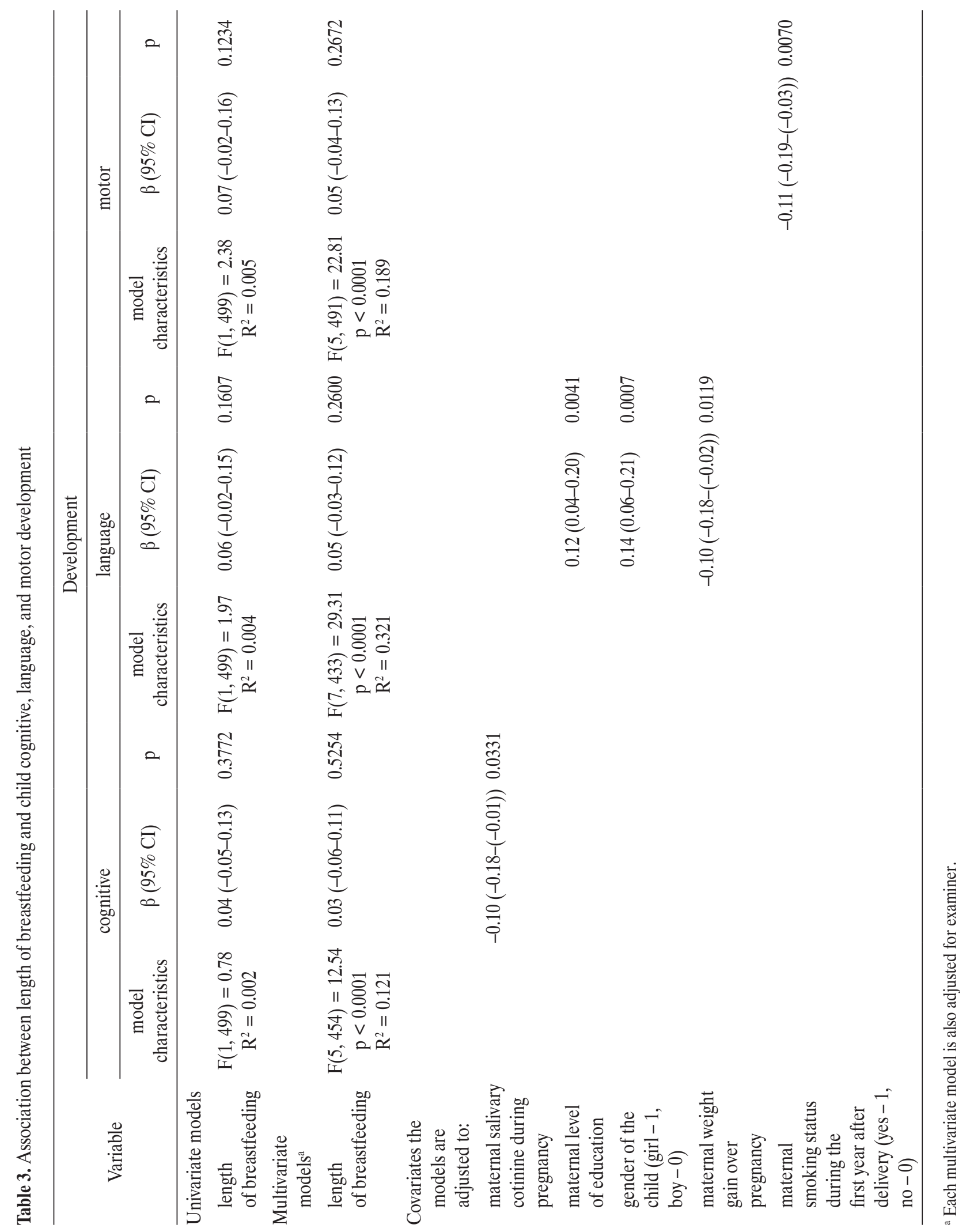


Der et al. [25] and Home et al. [26] showed that maternal IQ and/or educational level are the factors impacting on the child's mental abilities. In this analysis, the authors found that maternal education correlated significantly with language development. Mothers with a higher level of education are more likely to provide a stimulating environment for their infants.

The role of maternal weight gain in the psychomotor development of children has received no attention and a majority of studies consider maternal weight gain only in terms of premature birth rates. The observed negative correlation between the language development function and maternal weight gain, similarly to another study [27], was not clear. The maternal weight gain was found to be associated with offspring being overweight; it was probably the latter factor that might have been implicated in the poorer language function.

In current study, the authors observed that gender of the child (girls) was a significant confounder of an association between the duration of breastfeeding and language development. Whitehouse et al. concluded that breastfeeding for longer periods in early life has a positive effect on language development in middle childhood [28]. In another study [29], it was demonstrated that breastfed children had Peabody Picture Vocabulary Test scores that were 6.6 pts higher than those of children who were not breastfeed. Authors revealed that, among mothers with education beyond high school, the test scores in adjusted models were 2.2 pts higher for breastfed children; among mothers with a high school diploma or less, there were no significant differences in children's test scores by breastfeeding status.

In addition, a negative association between maternal smoking status during the first year after delivery and child motor development was found. Other studies have produced similar results [30,31].

Several limitations of this study should be noted. It needs to be pointed out that, although the Bayley test is wildly used for child neurodevelopment assessment within first years of life, for 1-year-old infants it could be less reliable and more situation sensitive for them than for older children. In the current study, the authors repeated child psychomotor assessment at the age of 2 years; however, due to the smaller sample size, the data was not included in the analysis. Similarly, taking into consideration that only 52 women in the examined cohort declared that their children were not breastfed, the analysis was limited solely to the length of breastfeeding. In addition, as the information regarding breastfeeding was collected at the time of child psychomotor assessment, some recall bias cannot be excluded. Parental IQ assessment was not performed in this cohort but the authors used the parents' educational levels as a proxy of this variable. Finally, the Home Observation Measurement of the Environment (HOME) should be addressed as the additional confounder in the analysis. Unfortunately such data was not available for 1-year-olds. It needs to be pointed out that REPRO_PL cohort is still an ongoing study which provides the opportunity to include more questions/ scales evaluating parent-child interactions or family functioning.

\section{CONCLUSIONS}

In this study the authors have shown that exclusive breastfeeding for $\geq 6$ months was not associated with psychomotor development in 1-year-old children, following adjustment for multiple confounders: maternal level of education, gender of the child, maternal weight gain and maternal smoking status. The authors suspect that the beneficial effects of breastfeeding duration on children's neurodevelopment may emerge only when breastfeeding occurs in conjunction with other positive parenting behavior.

\section{REFERENCES}

1. Berndt TJ. Child development. Orlando: Harcourt Brace Javanovich; 1992. 
2. Bacahrach VR, Baumeister AA. Effects of marital intelligence, marital status, income and home environment on cognitive development of low birthweight infants. J Pediatr Psychol. 1998;23(3):197-205, https://doi.org/10.1093/jpepsy/ 23.3.197.

3. Eickmann SH, de Lira PI, Lima Mde C, Coutinho SB, Teixeira Mde L, Ashworth A. Breast feeding and mental and motor development at 12 months in a low-income population in northeast Brazil. Paediatr Perinat Epidemiol. 2007;21(2):129-37, https://doi.org/10.1111/j.1365-3016. 2007.00795.x

4. Gibson-Davis CM, Brooks-Gunn J. Breastfeeding and verbal ability of 3-year-olds in a multicity sample. Pediatrics. 2006;118:e1444-51, https://doi.org/10.1542/peds.2006-0072.

5. Bernard JY, De Agostini M, Forhan A, Alfaiate T, Bonet M, Champion V, et al. Breastfeeding duration and cognitive development at 2 and 3 years of age in the EDEN motherchild cohort. J Pediatr. 2013;163(1):36-42, https://doi.org/ 10.1016/j.jpeds.2012.11.090.

6. Huang J, Peters KE, Vaughn MG, Witko C. Breastfeeding and trajectories of children's cognitive development. Dev Sci. 2014;17(3):452-61, https://doi.org/10.1111/desc.12136.

7. Belfort MB, Rifas-Shiman SL, Kleinman KP, Guthrie LB, Bellinger DC, Taveras EM, et al. Infant feeding and childhood cognition at ages 3 and 7 years: Effects of breastfeeding duration and exclusivity. JAMA Pediatr. 2013;167(9):83644, https://doi.org/10.1001/jamapediatrics.2013.455.

8. Quinn PJ, O'Callaghan M, Williams GM, Najman JM, Andersen MJ, Bor W. The effect of breastfeeding on child development at 5 years: A cohort study. J Paediatr Child Health. 2001;37:465-9, https://doi.org/10.1046/j.1440-1754. 2001.00702.x.

9. Angelsen NK, Vik T, Jacobsen G, Bakketeig LS. Breast feeding and cognitive development at age 1 and 5 years. Arch Dis Child. 2001;85(3):183-8, https://doi.org/10.1136/ adc.85.3.183.

10. Malloy M, Berendes H. Does breast-feeding influence intelligence quotients at 9 and 10 years of age? Early Hum
Dev. 1998;50(2):209-17, https://doi.org/10.1016/S0378-3732 (97)00044-1.

11. Richards M, Wadsworth M, Rahimi-Foroushani A, Hardy R, Kuh D, Paul A. Infant nutrition and cognitive development in the first offspring of a national UK birth cohort. Dev Med Child Neurol. 1998;40:163-7.

12. Jacobson SW, Jacobson JL. Breast feeding and intelligence. Lancet. 1992;339:926, https://doi.org/10.1016/01406736(92)90962-3.

13. Jacobson SW, Chiodo LM, Jacobson JL. Breastfeeding effects on intelligence quotient in 4- and 11-year old children. Pediatrics. 1999;103(5):e71, https://doi.org/10.1542/peds.103.5.e71.

14. Walfisch A, Sermer C, Cressman A, Koren G. Breast milk and cognitive development the role of confounders: A systematic review. BMJ Open. 2013;23;3(8):e003259.

15. Koletzko B, Lien E, Agostoni C, Bohles H, Campoy C, Cetin I, et al. The roles of long chain polyunsaturated fatty acids in pregnancy, lactation and infancy: Review of current knowledge and consensus recommendations. J Perinat Med. 2008;36:5-14, https://doi.org/10.1515/JPM.2008.001.

16. Lo A, Sienna J, Mamak E, Böhles H, Campoy C, Cetin I, et al. The effects of maternal supplementation of polyunsaturated fatty acids on visual, neurobehavioural, and developmental outcomes of the child: A systematic review of the randomized trials. Obstet Gynecol Int. 2012;591531.

17. Jain A, Concato J, Leventhal JM. How good is the evidence linking breastfeeding and intelligence? Pediatrics. 2002;109 (6):1044-53, https://doi.org/10.1542/peds.109.6.1044.

18. Polańska K, Hanke W, Gromadzińska J, Ligocka D, Gulczyńska E, Sobala W, et al. Polish Mother and Child Cohort study - Defining the problem, the aim of the study and methodological assumptions. Int J Occup Med Environ Health. 2009;22(4):383-91.

19. Polańska K, Hanke W, Jurewicz J, Sobala W, Madsen C, Nafstad P, et al. Polish Mother and Child Cohort study (REPRO_PL) - Methodology of follow-up of the children. Int J Occup Med Environ Health. 2011;24(4):391-8, https://doi. org/10.2478/s13382-011-0026-y. 
20. Polanska K, Hanke W, Sobala W, Trzcinka-Ochocka M, Ligocka D, Brzeznicki S, et al. Developmental effects of exposures to environmental factors: The Polish Mother and Child Cohort Study. Biomed Res Int. 2013;2013:629716.

21. Polanska K, Hanke W, Krol A, Gromadzinska J, Kuras R, Janasik B, et al. Micronutrients during pregnancy and child psychomotor development: Opposite effects of zinc and selenium. Environ Res. 2017;158:583-9, https://doi.org/ 10.1016/j.envres.2017.06.037.

22. Polanska K, Krol A, Sobala W, Gromadzinska J, Brodzka R, Calamandrei G, et al. Selenium status during pregnancy and child psychomotor development - Polish Mother and Child Cohort study. Pediatr Res. 2016;79(6):863-9, https://doi. org/10.1038/pr.2016.32.

23. Polańska K, Muszyński P, Sobala W, Dziewirska E, MereczKot D, Hanke W. Maternal lifestyle during pregnancy and child psychomotor development - Polish Mother and Child Cohort study. Early Hum Dev. 2015;91(5):317-25, https:// doi.org/10.1016/j.earlhumdev.2015.03.002.

24. Paine BJ, Makrides M, Gibson RA. Duration of breast feeding and Bayley's Mental Developmental Index at 1 year of age. J Paediatr Child Health. 1999;35(1):82-5, https://doi. org/10.1046/j.1440-1754.1999.00331.x.

25. Der G, Batty GD, Deary IJ. Effect of breast feeding on intelligence in children: Prospective study, sibling pairs analysis, and meta-analysis. BMJ. 2006;333:945, https://doi. org/10.1136/bmj.38978.699583.55.
26. Holme A, MacArthur C, Lancashire R. The effects of breastfeeding on cognitive and neurological development of children at 9 years. Child Care Health Dev. 2010;36(4):583-90, https://doi.org/10.1111/j.1365-2214.2009.01068.x.

27. Jedrychowski W, Perera F, Jankowski J, Butscher M, Mroz E, Flak E, et al. Effect of exclusive breastfeeding on the development of children's cognitive function in the Krakow prospective birth cohort study. Eur J Pediatr. 2012;171(1):151-8. 28. Whitehouse AJ, Robinson M, Li J, Oddy WH. Duration of breast feeding and language ability in middle childhood. Paediatr Perinat Epidemiol. 2011;25(1):44-52, https://doi. org/10.1111/j.1365-3016.2010.01161.x.

29. Gibson-Davis CM, Brooks-Gunn J. Breastfeeding and verbal ability of 3-year-olds in a multicity sample. Pediatrics. 2006;118(5):e1444-51, https://doi.org/10.1542/peds.2006-0072.

30. Herrmann M, King K, Weitzman M. Prenatal tobacco smoke and postnatal secondhand smoke exposure and child neurodevelopment. Curr Opin Pediatr. 2008;20(2):184-90, https:// doi.org/10.1097/MOP.0b013e3282f56165.

31. Polańska K, Jurewicz J, Hanke W. Smoking and alcohol drinking during pregnancy as the risk factors for poor child neurodevelopment - A review of epidemiological studies. Int J Occup Med Environ Health. 2015;28(3):419-43, https://doi.org/10.13075/ijomeh.1896.00424.

This work is available in Open Access model and licensed under a Creative Commons Attribution-NonCommercial 3.0 Poland License - http://creativecommons.org/ licenses/by-nc/3.0/pl/deed.en. 